\title{
Iconografía precolombina del Ecuador. Aplicación en obras de arte sobre materiales alternativos
}

Pre-Columbian iconography of Ecuador. Application in works of art on alternative materials

Ruth Jacqueline Simaluiza Masabanda

Departamento de Arquitectura y Arte, Universidad Técnica Particular de Loja, Ecuador (rjsimaluiza@utpl.edu.ec)

Recibido el 02 de mayo de 2018; revisado el 13 de mayo de 2018; aceptado el 22 de mayo de 2018; publicado el 12 de julio de 2018

RESUMEN: En este artículo se presenta una breve reseña de la arqueología en el Ecuador con el fin de enmarcar las culturas originarias con respecto al tiempo; la descripción de las culturas de la región costa del Ecuador, de acuerdo a la periodización que propuso el arqueólogo autodidacta Emilio Estrada Ycaza y los arqueólogos Clifford Evans y Betty Meggers, con reajustes cronológicos propuestos por el arqueólogo Santiago Ontaneda y; por último una propuesta original de aplicación de la iconografía precolombina en obras de arte sobre materiales alternativos a partir del análisis geométrico de las imágenes de los objetos originales.

PALABRAS CLAVE: Culturas originarias, Iconografía precolombina, Materiales alternativos, Sellos precolombinos.

\begin{abstract}
This paper presents a brief review of archeology in Ecuador for focusing the original cultures with respect the time; a description of the pre-Columbian cultures of the coastal region of Ecuador, according to the periodization proposed by the self-taught archaeologist Emilio Estrada Ycaza and the archaeologists Clifford Evans and Betty Meggers, with readjustments of time proposed by the archaeologist Santiago Ontaneda; and finally, the description of a new application of preColumbian iconography in works of art on alternative materials based on geometric analysis of the imagens from the original objects.
\end{abstract}

KEYWORDS: Original cultures, Pre-Columbian iconography, Alternative materials, Pre-Columbian stamps. 
Los escritos que tenemos respecto al Ecuador originario son escasos; sin embargo, existen algunas crónicas en las que se registró lo que los españoles observaron al llegar a estas zonas. No obstante, el origen de la cultura de Ecuador se remite a épocas mucho más antiguas, que se pueden conocer por los hallazgos arqueológicos encontrados en el territorio nacional.

Estos registros arqueológicos dan pie a estudios de diversa índole, por ejemplo, etnológicos, sociológicos, históricos, arquitectónicos, etc. Asimismo, la cantidad de objetos que se han encontrado dan la posibilidad de abrir nuevos campos de estudio, como es el caso del análisis de la iconografía subyacente en los diferentes objetos elaborados por los habitantes de las culturas originarias. Desde esta perspectiva, el diseño puede ser una herramienta que permite ahondar en el estudio de los diferentes motivos decorativos presentes en los objetos cerámicos. Si bien estos objetos presentan un sinnúmero de formas, este artículo se centra en el análisis de alguno de los sellos planos perteneciente a la cultura Manteño Huancavilca, los mismos que serán primeramente contextualizados históricamente y analizados gráficamente para finalmente poder aplicar la iconografía precolombina sobre materiales alternativos.

\section{Los pueblos precolombinos de Ecuador}

Tomando como referencia el clima y el tipo de territorio, la parte sur de América -en la que se localiza el Ecuador- tiene tres constantes que definen lo que es "el área andina: el océano Pacífico al occidente, la cordillera al centro, y la selva al oriente. La coexistencia de esos elementos no tendría nada de particular si no fuera porque representan una unidad natural de permanente relación dialéctica, que fue a la larga un factor muy importante en el desarrollo de la civilización y en las características del poblamiento andino" (Lumbreras, 1981, pp. 40-41).

Al tener en cuenta esta referencia es posible asumir que los primeros habitantes de lo que hoy es Ecuador llegaron hace unos 13.000 años o más. Sin embargo, lo que se conoce sobre los pueblos originarios de este país procede de las excavaciones arqueológicas [1], las cuales evidencian parte de su forma de vida y de la existencia de una relación transversal entre las diferentes regiones de Ecuador. 


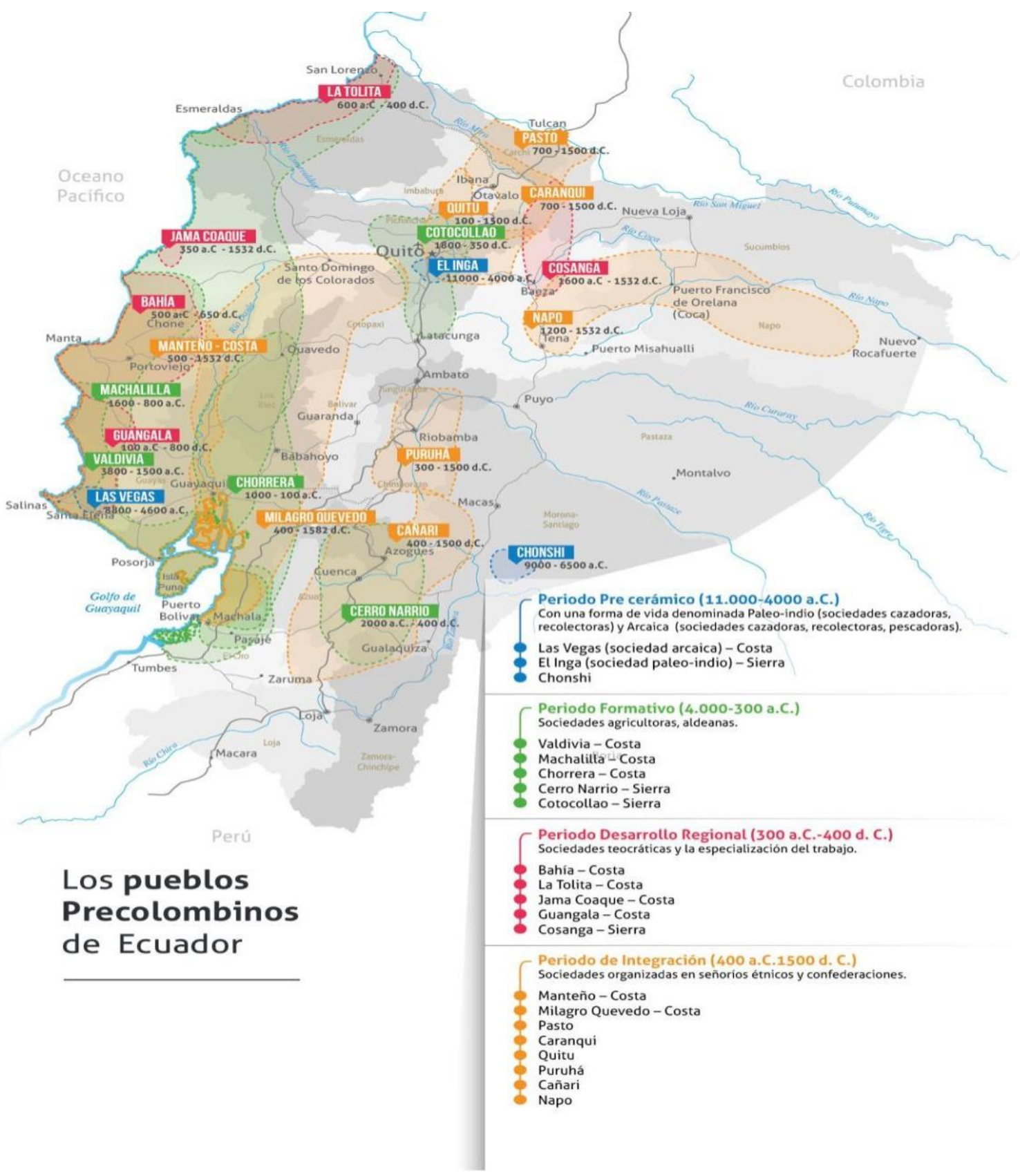

1. Los pueblos Precolombinos de Ecuador. Elaboración propia

Al haber mencionado que parte de lo que conocemos del Ecuador antiguo es por las excavaciones arqueológicas, es importante destacar el trabajo del arqueólogo autodidacta Emilio Estrada Ycaza y los arqueólogos Clifford Evans y Betty Meggers quienes difundieron como herramienta heurística, entre 1957 y 1966, el esquema cronológico del Área Septentrional Andina (Echeverría, 1996, p. 8), aunque en la presente investigación hemos admitido los reajustes de tiempos propuestos por el arqueólogo Santiago Ontaneda que difundió en el 2010 en su libro Las Antiguas Sociedades precolombinas del Ecuador. 
De acuerdo a esta secuencia cronológica se identifican las siguientes culturas a lo largo y ancho del Ecuador como son:

\begin{tabular}{|l|l|l|}
\hline Precerámico & $11.000-4000$ a.C. \\
\hline \multirow{3}{*}{ Formativo } & Temprano & $3400-1500$ a.C. \\
\cline { 2 - 3 } & Medio & $1500-1000$ a.C. \\
\cline { 2 - 3 } & Tardío & $1000-300$ a.C. \\
\hline Desarrollo Regional & 300 a.C.-400 d.C. \\
\hline Integración & $400-1500 / 1532$ d.C. \\
\hline
\end{tabular}

Tabla 1. Etapas arqueológicas de lo que hoy es Ecuador, según los arqueólogos Evans y Meggers, incluyendo el periodo de integración aportado por Ontaneda.

De estas culturas se toma como referencia una milésima parte de la Cultura Manteño Huancavilca (500-1532 d. C) del periodo de integración. En el periodo de integración los pueblos conformaron alianzas ${ }^{1}$, colocando al mando a un curaca o señorío étnico. Esta integración progresiva ayudó a generar redes de intercambio entre la costa y demás lugares aledaños, siendo los mercaderes o mindaláes un ente importante de desarrollo en la organización social. En la conformación de esta red comercial es importante mencionar que cada sector se especializó en la producción de diferentes bienes, como son la producción de cerámica, tejidos, metalurgia, la agricultura, "bienes suntuarios como las hojas de coca, sal de mina, concha spondylus ${ }^{2}$, o materias primas como el algodón para la fabricación de mantas y el oro aluvial para la elaboración de adornos” (Ontaneda, 2010, p. 157).

Por otro lado, uno de los argumentos de cambio de un periodo a otro es la cerámica, ya que su estilo adopta otras soluciones decorativas, Borchart y Moreno mencionan: "Efectivamente los decorados rojos se opacaron, los grises fueron reemplazados por el negro bruñido y se generalizó una mayor sobriedad" (1997, pp. 51-52).

\footnotetext{
${ }^{1}$ Investigaciones más recientes están descubriendo un extenso y complejo patrón de centros urbanos pertenecientes a las formaciones para-estatales Manteño Huancavilca en yacimentos como Los Frailes, Agua Blanca, López Viejo, Río Ayampe, Loma de los Cangrejitos y los del Cerro de Chanduy y su entorno. (Marcos, 2005, p. 33).

2 "En el caso de Ecuador, es para el período de Integración (900 a.C. 1530 d.C.) que se comienza a dejar de exportar una parte importante (de concha spondylus), para confeccionar cantidades de cuentas rojas, y se conservan espinas rojas para su empleo funerario en tumbas de la cultura Manteña. Este incremento significaría que la élite costeña ya consideraba a la spondylus "no solo como un artículo de comercio valioso, sino también como un artículo que merecía llevarse en su viaje al Otro Mundo" (Marcos, 1986, p. 173).
} 


\section{Morfología de la iconografía precolombina: Morfología y estructura de los sellos precolombinos}

Para el estudio del presente artículo se escogieron sellos, que son objetos volumétricos -concretamente piezas de relieves para estampar, con un saliente o asa para manejar esta función- la mayoría con formas orgánicas; tienen imágenes geométricas que presentan figuras bidimensionales compuestas a partir de figuras geométricas simples, como el círculo, el triángulo y el cuadrado (en la figura [2] se muestra la cara anterior y posterior de uno de los sellos estudiados). A continuación, se presenta el análisis de los sellos en cuanto a objeto, gráfica y función.
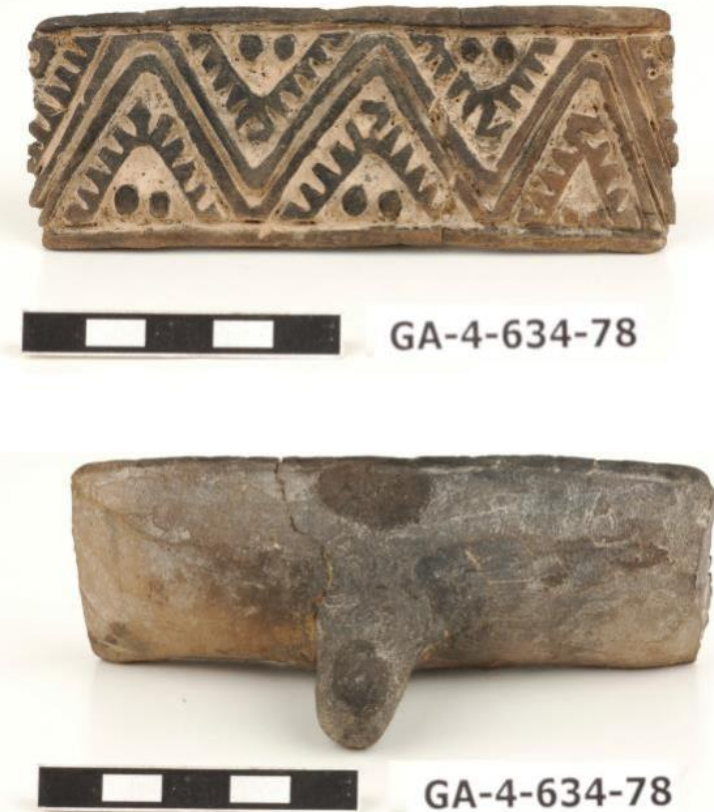

2. Partes de un sello precolombino. Sello plano estilización zoomorfa de la Cultura Manteño Huancavilca-Inventario administrativo: GA-4-634-78 [Fotografía]. Archivo fotográfico de Centro Cultural Libertador Simón Bolívar de Guayaquil (MAAC).

Con el fin de hacer un estudio gráfico de los motivos precolombinos, hemos recurrido a realizar una descripción del sello como objeto y su función; así también, una breve descripción gráfica. Al describir el sello como objeto en consonancia al método proyectual de Bruno Munari, podríamos decir de forma general lo siguiente:

El objeto se denomina sello y fue creado por artesanos de las culturas originarias, las dimensiones de los sellos miden entre 8 y $10 \mathrm{~cm}$ de largo; 5 y $8 \mathrm{~cm}$ de alto y 5 de profundidad; el material que utilizaron es la mezcla de arcilla con arena. Por su forma, el objeto responde a la necesidad 
de reproducir motivos gráficos. Es por esta razón que puede ser plano, para reproducir un motivo individualizado; o cilíndrico, para reproducir un motivo continuo. Además, debieron de requerir limpieza continua por la acumulación de pigmento. Asimismo, podemos decir que este objeto tiene un valor social, ya que permitió dejar constancia de la forma de concebir el mundo, puesto que en la gráfica se representa en muchos de los casos, el entorno.

De esta manera podemos decir que, "La forma gráfica está constituida por elementos conceptuales, visuales, de relación y prácticos" (Wong, 1995, p. 42), por lo que en este estudio denominamos gráfica — como signo visual en los sellos precolombinos - al huecograbado que se localiza en la parte plana del sello. La función, es posible que fueran elaborados con el fin de reproducir los diferentes motivos en pintura o en alto y bajo relieve sobre cerámica.

\section{Interpretación de signos y símbolos precolombinos}

Como hemos visto anteriormente, las sociedades precolombinas en la medida en que se iban transformando, incorporaron acciones como la comunicación a través de un lenguaje icónico. Para entender esta afirmación, partimos de la interpretación que hace Pierce al decir: "un signo es algo que representa algo para alguien en algún aspecto o carácter" (1987, p. 244). Esto incluye tres elementos funcionales: el signo, el objeto y el intérprete, los mismos que se definen de acuerdo a sus relaciones, que en este caso hemos tomado en cuenta como un tipo de signo al icono, sobre todo porque la gráfica tiene una similitud con el objeto. de esta manera podemos afirmar que un icono se parece al objeto.

Al hacer referencia a uno de los sellos podemos hacer una breve descripción icónica en la que observamos de forma clara, la representación icónica [3].

- Las imágenes nos muestran la reproducción de las cabezas de caballitos de mar.

- En el sello se reproducen ciertas características físicas como los ojos, el tubo bucal y la corona.

- A pesar de haber sido reducida la cabeza a la máxima expresión, sabemos que el sello tiene similitud con el objeto representado.

- La imagen fotografiada nos muestra un mayor grado de iconicidad; sin embargo, la imagen plasmada en el sello cumple con el objeto de reproducirlo.

- La imagen del sello está colocada en un contexto de representación por semejanza frente a la fotografía; no obstante, ambas nos sitúan en un nivel icónico. 

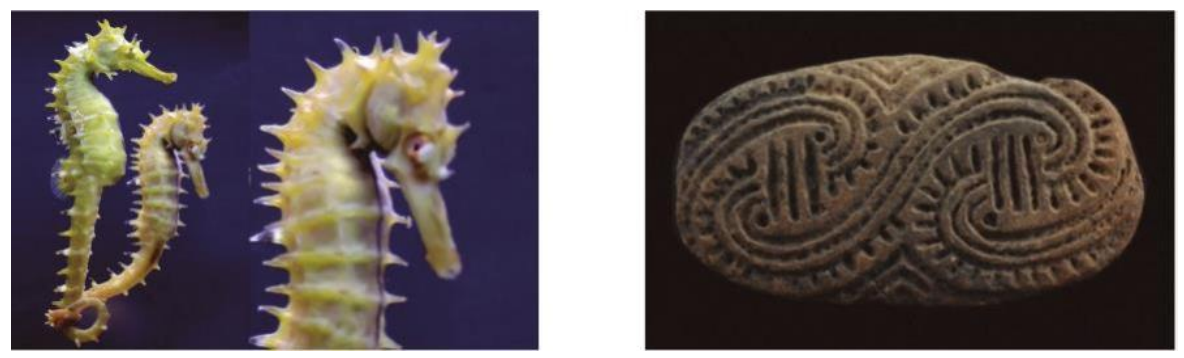

3. Semejanza de la imagen de un caballito de mar con la estilización de una posible cabeza de caballito de mar. a) Caballito de mar [imagen] https://maricarmenyjavi.files.wordpress.com/2014/05/wpid-sea_04.jpeg. (15-11-2015). b) Colección Arqueológica del MAAC del Ministerio de Cultura y Patrimonio del Ecuador. Reproducción estilizada de un caballito de mar en el sello. (2015-06-09)

\section{Esquematización o idealización de la forma}

En este apartado se describe el análisis gráfico del sello que se muestra en la figura 2, siguiendo una metodología propia, el cual nos permite distinguir los elementos geométricos que constituyen las imágenes de los mismos. En primer lugar, se estudia gráficamente la imagen del sello, para posteriormente agregar una interpretación creativa de la imagen; damos a conocer dos de las fases que hemos propuesto para poner en valor nuestro estudio:

a) Estudio gráfico sobre la foto de la pieza, en el que se presenta el dibujo de forma digital, guardando en lo posible su forma original, con el fin de generar un repositorio de imágenes precolombinas de acuerdo a los parámetros con los que fueron creadas.

b) Trazado del esquema geométrico subyacente en el sello, en el que se muestra un esquema explicativo de las proporciones y reglas básicas del trazado del motivo [4]. Esto con el fin de analizar el diseño y poder crear nuevas propuestas a partir de los parámetros encontrados.

De esta forma podemos indicar que, de acuerdo al trazo sobre el motivo, se puede decir que es uno de los sellos que menos precisión muestra en su ejecución: A pesar de la aparente intención del autor de ser un motivo repetitivo existe una diferencia notable de las proporciones de los diferentes triángulos. Sin embargo, al hacer un reajuste, el sello se encuentra enmarcado en un rectángulo que se forma a partir de la secuencia de tres cuadrados yuxtapuestos. Por su composición, existen dos simetrías, una simetría de traslación que permite repetir el motivo indefinidamente; una simetría 
central cuyo centro de simetría es el punto medio de cada uno de los lados iguales de cada triángulo isósceles.

Dado un motivo con forma de triángulo isósceles y aplicando las simetrías mencionadas se obtiene el sello al completo. Además, puesto que el motivo tiene una simetría axial cuyo eje es la altura del triángulo, el sello también es preservado por esta simetría.

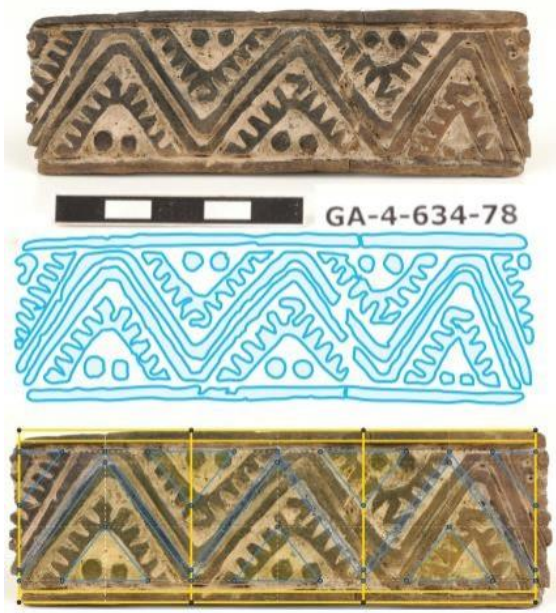

4. Sello plano estilización zoomorfa de la Cultura Manteño Huancavilca-Inventario administrativo: GA-4-634-78

[Fotografía]. Archivo fotográfico de Centro Cultural Libertador Simón Bolívar de Guayaquil (MAAC).

\section{Aplicación de la iconografía precolombina sobre materiales alternativos}

A través de esta forma de trabajo se pone en valor una parte del legado patrimonial y artístico de los pueblos originarios ya que se han tomado como motivos imágenes seleccionadas para recrearlas en nuevas obras de arte, en las que se busca combinar la noción artística precolombina; la diversidad natural de la zona amazónica ecuatoriana, al emplear materiales provenientes de esa área geográfica; y técnicas actuales de diseño, que mediante la creatividad propia del artista, permiten explorar nuevas rutas de encuentro entre el pasado aborigen y la realidad de este siglo.

La propuesta artística que presentamos tiene como temática la iconografía precolombina de Ecuador [5], a partir del análisis gráfico de los sellos seleccionados, a fin de tomar esta iconografía como motivo para proyectar trabajos de diseño u obras de arte. Las obras usan, como soporte, papel de fibras vegetales de abacá; en cuanto a la técnica se utilizaron colorantes naturales que se obtienen de forma directa de raíces, semillas, hojas y frutos de algunas plantas; la mayoría extraídas de la zona amazónica del Ecuador. Estos colorantes son estudiados por un grupo de investigación de los 
Departamentos de Arquitectura y Arte, Química y Ciencias Naturales de la Universidad Técnica Particular de Loja (Ecuador). En este trabajo se ha elegido este tipo de colorantes, por la armonía que guarda con los vestigios de las culturas originarias y que permiten acercarse más al sentido artístico de estos pueblos.

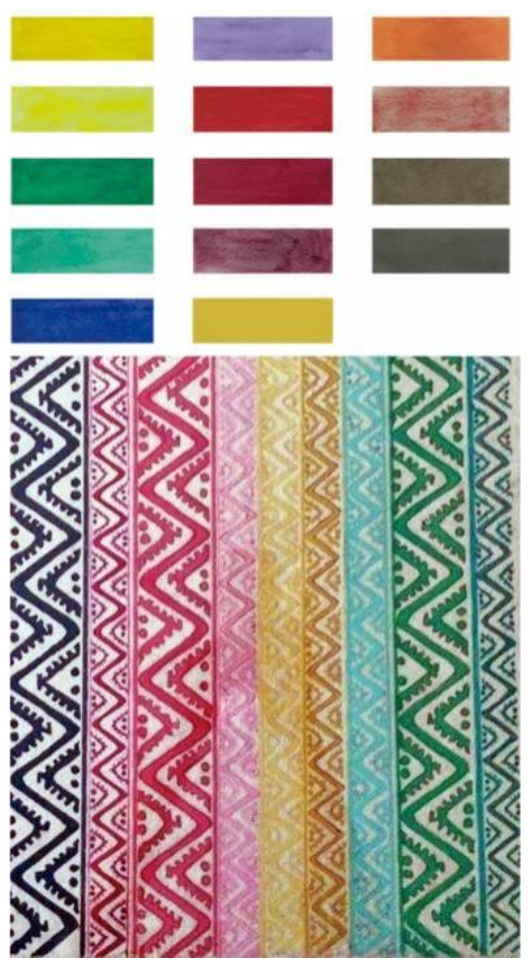

5. a) Paleta de colores que se utilizará de acuerdo a los colorantes escogidos para el presente trabajo. b) Obra de arte. Material del soporte: Papel de fibra natural-abacá. Tamaño del soporte: 29x21 cm. Técnica: Aguada y aplicación de colorantes con pincel. Elaboración propia.

\section{Conclusiones}

El estudio de la cultura material existente es una constatación de que las sociedades de ese entonces buscaron una forma de comunicarse, pues cada objeto es una evidencia de la forma de concebir el mundo. El análisis realizado a los referentes gráficos presentes en los diferentes utensilios de las culturas originarias permiten descubrir algunos rasgos de su forma de concebir el entorno. Para este estudio se seleccionó una serie de sellos, los cuales pueden considerarse como un elemento distintivo de un lugar, pues refleja la visión que los pobladores de Ecuador tuvieron de su realidad. El diseño de nuevas obras de arte combinando la gráfica precolombina, un soporte de origen natural y colorantes vegetales extraídos de la Amazonía; abre un camino para explorar nuevas rutas de encuentro entre el pasado aborigen y la realidad de este siglo. 


\section{Referencias bibliográficas}

ECHEVERRÍA, José (1996). Betty J. Meggers. Personalidades y dilemas en la arqueología ecuatoriana. Ediciones Abya-Yala, Quito.

GARCÍA-GARRIDO, Sebastián. (2015). Diseñar para una era humanista: Innovación transversal entre Arte, Diseño y Artesanado. IED Madrid, Madrid.

LUMBRERAS, Luis (1981). Arqueología de la América Andina. Editorial Milla Batres, Lima.

MARCOS, Jorge. (1986). De ida y vuelta a Acapulco con mercaderes de Mullu. Corporación Editora Nacional-Espol, Quito.

MARCOS, Jorge. (2005). Los Pueblos Navegantes del Ecuador Prehispánico. Ediciones Abya-Yala, Quito.

MUNARI, Bruno (1981). ¿Cómo nacen los objetos? España, Gustavo Gili, Barcelona.

Neuman, Giti (1994). Manual para la elaboración de papel hecho a mano a partir de fibras naturales. Giti Neuman Galería de Arte, Quito.

ONTANEDA, Santiago (2010). Las Antiguas Sociedades precolombinas del Ecuador. Nuevo Arte, Quito.

PIERCE, Charles S. (1987). Obra lógico semiótica. Taurus, Madrid.

WONG, Wucius (1995). Fundamentos del diseño. Gustavo Gili, Naucalpan-México. 